\title{
Alaca Çayı Havzası Erozyon Durumunun Morfometrik Ölçümler ile İlişkisi
}

\author{
Ali İmamoğlu ${ }^{*}$ \\ ${ }^{1}$ Nevşehir Hacı Bektaş Veli Üniversitesi Fen Edebiyat Fakültesi Coğrafya Bölümü, Nevşehir, Türkiye (ORCID: 0000-0001-9197-1029)
}

(İlk Geliş Tarihi 01 Şubat 2020 ve Kabul Tarihi 31 Mart 2020)

(DOI: $10.31590 /$ ejosat.710987)

ATIF/REFERENCE: İmamoğlu, A. (2020). Alaca Çayı Havzası Erozyon Durumunun Morfometrik Ölçümler ile İlişkisi. Avrupa Bilim ve Teknoloji Dergisi, (18), 868-878.

$\ddot{O} \mathbf{z}$

Erozyon tarım ve mera alanlarının sürdürülebilir kullanımı konusunda önemli bir problem olarak karşımıza çıkmaktadır. Coğrafi Bilgi Sistemleri programları ile havza çalışmalarında kullanılan morfometrik yöntemlerin kullanımı da yaygınlaşmıştır. Coğrafi Bilgi Sistemleri ile morfometrik hesaplamalar kolaylıkla yapılabilmekte ve doğru sonuçlar elde edilebilmektedir. Bu çalışma morfometrik özellikler ile erozyon ilişkisini ortaya koymak amacılya gerçekleştirilmiştir.

Çalışma alanı Alaca Havzası seçilmiştir. Havza Orta Karadeniz Bölümü’nde, Çorum ile Yozgat illeri içerisinde yer almaktadır. Havzanın toplam alanı $1656.4 \mathrm{~km}^{2}$ 'dir. Alaca Çayı havzası, Yeşilırmak'ın su toplama havzasında bulunur. Havza Kızılırmak havzası ile sınırında yer almaktadır. Saha Alaca Çayı tarafından drene edilmekte ve bu akarsu araştırma sahasından çıkınca Çorum Çayı ve Çekerek ırmağıyla birleşmektedir.

Araştırmada havzanın çevre uzunluğu, havza alanı, havza uzunluğu, maksimum ve minimum yükseklik, çatallanma oranı, Hipsometrik Eğri Analizi, Drenaj Yoğunluğu, Akarsu Sıklığı, Tekstür Oranı, Havza Reliefi, Engebelilik Değeri, Havza Şekli Analizi, Şekil İndeks değeri, Gravelius İndeks, Uzunluk Oranı, Form Faktörü incelenmiştir. Bu hesaplamalar yapılırken ArcGIS 10.3 programından faydalanılmıştır. Elde edilen sonuçlar arazi çalışmaları sırasında yapılan gözlemler ile doğrulanmıştır.

Havza genelinde drenaj yoğunluğu değeri $0.4^{\prime}$ tür. Alaca havzasının alanının büyük fakat yoğunluğun düşük olması, havzanın infiltrasyona elverişli koşullar sunduğu sonucunu ortaya koymuştur. Havzanın yükselti ve eğim değerlerinin arttığı yerlerinde erozif faaliyetler artarken havza şekline bağlı olarak özellikle eğim değerlerinin düştüğü yerlerde erozyon miktarı düşüktür. Akarsu havzasında yapılan morfometrik analizler sonucunda; çatallanma oranına göre birinci dizinlerin bulunduğu sahalarda erozyonal şekillerin yaygın olduğu görülmüştür. Havzanın yuvarlak şekline bağlı olarak zaman zaman sağanak yağışlar sonrasında akarsu seviyesi aniden yükselmekte ve şiddetli erozyon yaşanmaktadır. Bu çalışma erozyonal süreçlerinin incelenmesi konusunda morfometrik indislerin önemini ortaya koymaktadır.

\section{Relation of Erosion Status with Morphometric Measurement in Alaca Stream Basin}

\begin{abstract}
Erosion is an important problem in the sustainable use of agriculture and pasture lands. The use of morphometric methods used in watershed studies has also become widespread with Geographic Information Systems programs. Morphometric calculations can be
\end{abstract}

\footnotetext{
* Sorumlu Yazar: Nevşehir Hacı Bektaş Veli Üniversitesi Fen Edebiyat Fakültesi Coğrafya Bölümü, Nevşehir, Türkiye (ORCID: 0000-0001-91971029), aliimamoglu@yandex.com
} 
made easily with Geographical Information Systems and accurate results can be obtained.This study was carried out to reveal the relationship between morphometric properties and erosion.

This study was carried out in Alaca Watershed. This watershed located at between Çorum and Yozgat provinces in Central Blacksea Region. Total area of the study area is $1656.4 \mathrm{~km}^{2}$. Alaca Stream basin is located in Yeşilırmak's water collection basin. The basin forms a border with the Kizılirmak basin. Alaca stream collects the water of the field and when this stream leaves the research area, it combines with Çorum Stream and Çekerek river.

In the study, the circumference of the basin, basin area, basin length, maximum and minimum height, bifurcation rate, Hypsometric Curve Analysis, Drainage Density, Stream Frequency, Texture Rate, Basin Relief, Roughness Value, Basin Shape Analysis, Shape Index value, Gravelius Index, Length The ratio, Form Factor was examined. ArcGIS 10.3 program was used while making these calculations. The results obtained were confirmed by observations made during field studies.

The drainage density value across the basin is 0.4. The fact that the area of the Alaca basin is large but the density is low revealed that the basin offers favorable conditions for infiltration. While erosive activities increase in places where elevation and slope values of the basin increase, the amount of erosion is low, especially where the slope values decrease depending on the basin shape. As a result of morphometric analysis in the river basin; According to the bifurcation rate, it has been observed that erosional shapes are common in the areas where the first knees are located. Depending on the round shape of the basin, after the occasional downpours, the river level suddenly rises and severe erosion is experienced. This study reveals the importance of morphometric indices for the examination of erosional processes.

Keywords: Erosion, Morphometry, Alaca Stream.

\section{Giriş}

Erozyon tarım ve mera alanlarının sürdürülebilir kullanımını sağlanması konusunda önemli bir problem olarak karşımıza çıkmaktadır. Son yıllarda, erozyonun tespitine ve önlenmesine yönelik yapılan araştırmalar daha çok modelsel çalışmalardır. Coğrafi bilgi sistemleri ile modelsel çalışmalar kolaylaşmış aynı zamanda doğal ortamın farklı morfometrik özellikleri de daha kolay ölçülebilir hale gelmiştir. Coğrafi Bilgi Sistemleri programları ile mevcut teknikler daha hızlı ve güvenilir olarak uygulanabilir hale gelmiştir. Bu tekniklerin kullanımı ile birlikte havza çalışmalarında kullanılan morfometrik yöntemlerin kullanımı da yaygınlaşmıştır. $\mathrm{Bu}$ alanda yapılan araştırmalarda; morfometrik analizler sonucu elde edilecek veriler ile havzanın morfolojik evriminin daha iyi yorumlanabilmesi ve havzada meydana gelebilecek doğal afetlerin derecelerinin anlaşılabilmesi hedeflenmiştir. Coğrafi Bilgi Sistemleri ile morfometrik hesaplamalar kolaylıkla yapılabilmekte ve hızlı ve güvenilir sonuçlar elde edilebilmektedir (Özdemir, 2007, 2011; Turoğlu, 2007; Aydın, 2008; Bahadır ve Özdemir, 2011; Bharadwaj vd., 2014; Uzun, 2014; Ghany, 2015; Turoğlu, 2016; Köle, 2016; Eraslan vd., 2017; Elbaşı ve Özdemir, 2018). Bu çalışma morfometrik özellikler ile erozyon ilişkisini ortaya koymaktadır.

Morfometri; farklı topografik şekillerin karşılaştırılması ve parametrelerin hesaplanmasında doğabilimcilerin daha nesnel olmasına yardımcı olur (Keller ve Pinter, 2002). Morfometri; topografik ölçümler yapılan matematiksel bir analiz yöntemidir (Agarwal, 1998; Reddy vd., 2002). Dünyanın farklı bölgelerinde akarsu havzalarında uygulanan morfometrik ölçümler havzaların farklı özelliklerinin incelenmesi ve ortaya konulmasında uygulanan önemli yöntemler ortaya koymuşlardır (Horton, 1945; Strahler, 1964; Kumar vd., 2000).

Havza çalışmalarında ele alınan indisler çok sayıda olmakla birlikte genellikle; çevre uzunluğu, havza alanı, havza uzunluğu, maksimum ve minimum yükseklik, toplam dizin sayısı ve uzunluğu, hipsometrik eğri analizi, çatallanma oranı, havza şekli, tekstür oranı, dairesellik oranı gibi indisler yaygın olarak kullanılmaktadır (Özdemir, 2011; Withanage vd., 2014; Avc1 ve Günek, 2015; Avc1 ve Sunkar, 2017; Bahadır vd., 2017; Altıparmak ve Türkoğlu, 2018; Fural, 2018; Utlu ve Özdemir, 2018 ).

Morfometrik analizler sonucunda havzanın doğal kaynaklarının yönetimi ile ilgili zorlukların azaltılacağı ve havza yönetiminin daha etkili olacağı düşünülmektedir (Martins ve Gadiga, 2015; Turoğlu ve Aykut, 2019). Bu sebeple havza çalışmalarında en başta uygulanacak yöntemlerin başında morfometrik ölçümler gelmektedir. Bu ölçümlerin cevap verebileceği önemli sorunlardan birisi de; havzanın erozyon duyarlılığı ve akış hidrografının davranışıyla ilgili yorum yapılabilecek çözümler üretmesidir (Görür ve Karadeniz, 2018). Bu araştırmada Alaca çayı havzasının bazı morfometrik özellikleri ölçülmüş ve elde edilen sonuçların erozyon ile ilişkisi tartışılmıştır. Elde edilen sonuçlar arazi çalışmaları sırasında yapılan gözlemler ile doğrulanmıştır.

\section{Materyal ve Metot}

\subsection{Araştırma Alanı Sınırları}

Araştırma sahası; İç Anadolu Bölgesi’nin Orta Kızılırmak Bölümü’nün kuzey kısmında bulunmaktadır. Orta Kızılırmak Bölümü ile Karadeniz Bölgesi'nin Orta Karadeniz Bölümü sınırında yer alır (Şekil 1). Araştırma sahası Alaca havzasının tamamından oluşmaktadır. Saha Alaca (Çorum) ilçesi dışında idari yönden Sorgun (Yozgat) ve Sungurlu (Çorum) ilçeleri sınırlarına da taşmaktadır.

Havza Yeşilırmak su toplama havzasında bulunur. Saha Alaca Çayı tarafından drene olmakta ve araştırma sahasından çıkınca Çorum Çayı ve Çekerek ırmağıyla birleşmektedir. Araştırma sahasında çok sayıda irili ufaklı baraj bulunmaktadır. Bu barajların en önemlisi Alaca ilçesinin içme suyu problemini de çözmesi planlanan, açılışı 2011 yılında yapılmış olan Çorum-Alaca-Koçhisar Barajı'dir.

Çalışma sahasının toplam alanı 1656,4 km²'dir. Araştırma sahası yükselti değerleri $825 \mathrm{~m}$ ile 1726 m aralığındadır. Araştırma sahasının güney kesimlerindeki dağlık alanlar Bozok platosunun kuzey kesimlerinde yer almaktadır. 
Alaca Çayı birçok kolun birleşmesiyle oluşur. Bu kollar Büyüköz Deresi, Evci Deresi, Kırımözü Deresi, Ağabayır Deresi, Eymir Deresi, Çaylanık Deresi ve Kurt Deresi’dir. Akarsuyun en önemli kolları; kaynaklarını Hırkababa Tepesi’nden alan Evci Deresi, kaynağını Akçadağ’dan alan Kırımözü Deresi ve kaynağını Toprakdede Tepesi’nden alan Eymir Deresidir. Yöredeki akarsuların birçoğu mevsimlik olup yaz aylarında kurumaktadır.

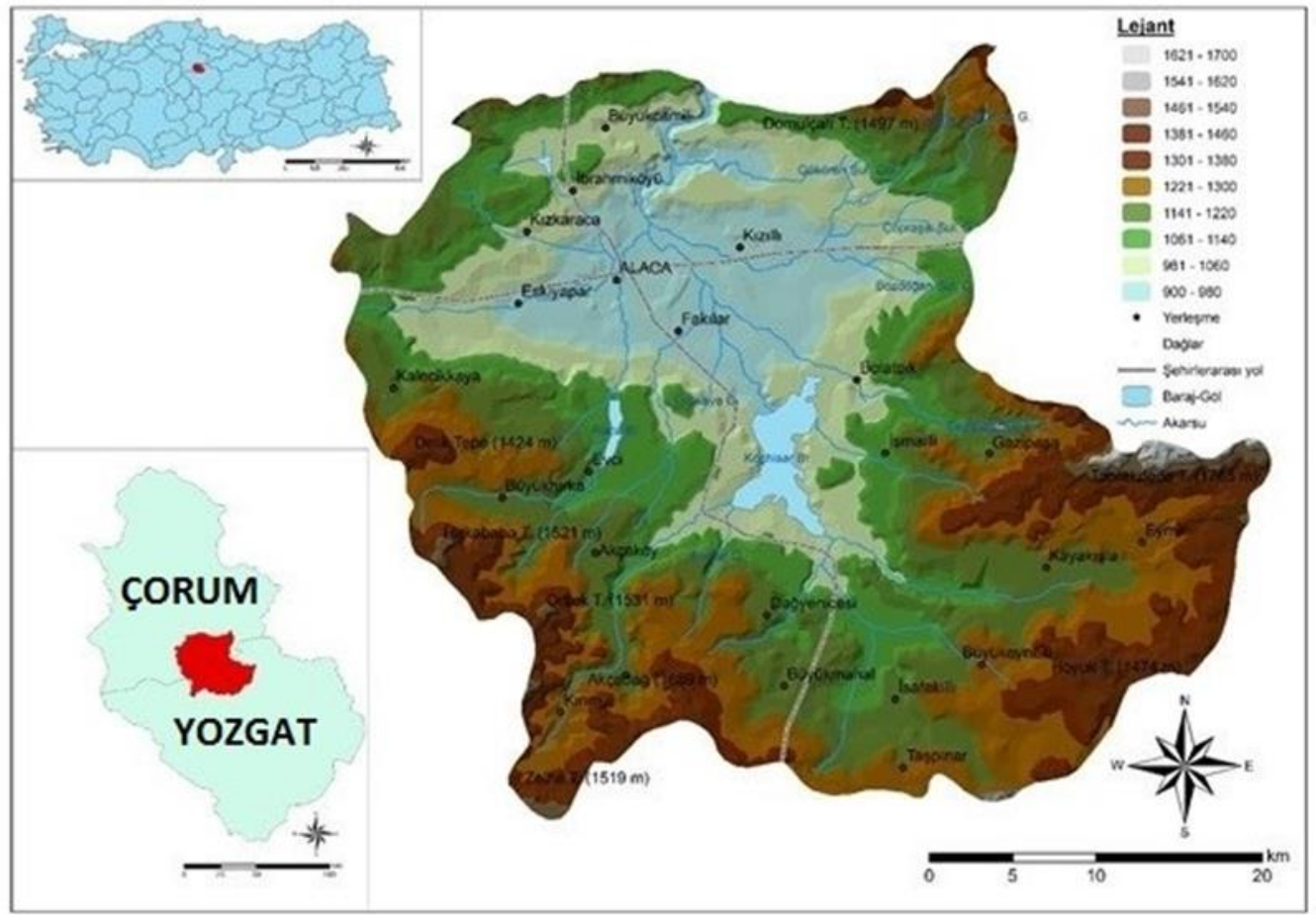

Şekil 1. Araştırma sahası lokasyon haritası

\subsection{Yöntem}

Havza çalışmalarında önemli parametrelerden olan bazı değerler morfometrik ölçümler ile yapılmaktadır. Bu ölçümler sonuvu elde edilen veriler başta erozyon ve taşkın olmak üzere sahada meydana gelebilecek olan doğal ortam problemlerinin ortaya konmasında ve bu problemlere karşı çözümcül yaklaşımlar ortaya konmasında önem arz eden verilerdir. Bu amaçla Alaca Çayı havzasında erozyon durumunun ortaya konulması amacıyla bazı morfometrik ölçümler gerçekleştirilmiştir. Elde edilen sonuçlar ile erozyon ilişkisi bütüncül bir yaklaşımla değerlendirilerek ortaya konulmuştur.

Araştırmada havzanın çevre uzunluğu, havza alanı, havza uzunluğu, maksimum ve minimum yükseklik toplam dizin uzunluğu ve sayısı değerleri Coğrafi Bilgi Sistemleri Arcgis programı yardımı ile hesaplanmış ve elde edilen sonuçlar kullanılarak tablo 1'de belirtilen yöntemler ile havzanın morfometrik parametrelier ortaya konulmuştur. 
Tablo 1. Araştırmada kullanılan yöntemler

\begin{tabular}{l|l|l}
\hline Morfometrik Parametre & Formül & Kaynak \\
\hline Çatallanma Oranı & $\mathrm{Rb}=\mathrm{Nu} / \mathrm{Nu}+1$ & Strahler, (1964) \\
\hline Hipsometrik Eğri Analizi & $\mathrm{Y}=\mathrm{h} / \mathrm{H} \quad \mathrm{X}=\mathrm{a} / \mathrm{A}$ & Keller ve Pinter, (2002) \\
\hline Drenaj Yoğunluğu & $\mathrm{Dd}=\Sigma \mathrm{L} / \mathrm{A}$ & Verstappen, (1983) \\
\hline Akarsu Sıklığı & $\mathrm{Fu}=\Sigma \mathrm{Nu} / \mathrm{A}$ & Horton, (1932) \\
\hline Tekstür Oranı & $\mathrm{T}=\mathrm{ND} 1 / \mathrm{P}$ & Reddy vd., (2004) \\
\hline Havza Reliefi & $\mathrm{Bh}=\mathrm{Hmax} .-\mathrm{Hmin.}$. & $\begin{array}{l}\text { Horton, (1945); Strahler, (1964); Baker } \\
\text { vd., (1988) }\end{array}$ \\
\hline Engebelilik Değeri & $\mathrm{R}_{\mathrm{h}}=\mathrm{B}_{\mathrm{h}} * \mathrm{D}_{\mathrm{d}}$ & Reddy vd., (2004) \\
\hline Havza Şekli Analizi & $\mathrm{R}_{\mathrm{f}}=\mathrm{A} / \mathrm{L}_{\mathrm{b}}^{2}$ & Horton, (1945); Verstappen, (1983) \\
\hline Şekil İndeks Değeri & $\mathrm{S}_{\mathrm{w}}=\frac{L}{W}=\frac{L 2}{A}$ & Horton, (1932) \\
\hline Gravelius İndeks & $\mathrm{K}_{\mathrm{c}}=0.28^{2} * \frac{P}{0.5 * A}$ & Gravelius, (1914) \\
\hline Uzunluk Oranı & $\mathrm{R}_{\mathrm{Q}}=\frac{2}{L m} *\left[\frac{A}{\pi}\right]^{0.5}$ & Reddy vd., (2004) \\
\hline Form Faktörü & $\mathrm{R}_{\mathrm{f}}=\mathrm{A} / \mathrm{L}_{\mathrm{b}}{ }^{2}$ & Reddy vd., (2004) \\
\hline
\end{tabular}

Y: Rölatif yükseklik, X: Rölatif alan, Nu: Dizin sayısı, $\Sigma$ : Toplam, ND1: Birinci dizinlerin toplamı, L $\mathrm{b}_{\mathrm{b}}$ : Havza uzunluğu, h: Değerlendirmeye alınan yükseklik (m), H: Havza reliefi, a: Alınan yükseklik üzerindeki gerçek alan değeri (m2), A: Havzanın gerçek alanı (m2), Pu=havzanın alanıyla aynı alana sahip çemberin çevresi, L: Ana akarsuya paralel havza uzunluğu(km), W: Ortalama genişlik (A/L), P: Havza çevre uzunluğu $(\mathrm{km})$, Lca: Havza ortasından ağza olan uzaklık (km), Lm: Havzanın maksimum uzunluğu $(\mathrm{km})$

\section{Araştırma Sonuçları ve Tartışma}

\subsection{Alaca Çayı Havzası Morfometrik Analizleri}

\subsection{Akarsu Ă̆ı ve Relief Özellikleri}

Akarsu ağı oluşturmak amacıyla SYM kullanılmıştır. SYM'den üretilecek olan akarsu ağının doğruluğunun yüksek olması için SYM'nin çözünürlüğünün yüksek olması gerekmekte, aksi takdirde düzlük sahalarda gerçek olmayan bir drenaj oluşabilmektedir (Maidment., 2002). Ayrıca SYM'nin içindeki hatalı ve boşluklu yerlerindüzeltilmesi gerekmektedir. Bu düzeltmenin sebebi oluşacak akarsu şebekesindeki bozuklukları engellemektir (Tarboton vd., 1991). Araştırmada düzeltilmiş SYM görüntüsü elde edilmiş ve akarsu havzasındaki doğal akış yönleri belirlenmiştir (Şekil 2).

Doğal akış haritasında yüzey sularının doğrudan akışa geçtiği kabul edilmektedir. Doğal akış yönleri toplamı doğal akımı verir. Sahada oluşabilecek maksimum akarsu ağını doğal akım ortaya koymaktadır. Bu değere göre havzanın akarsu akımlarındaki maksimum değerler kabaca hesaplanmaktır. 


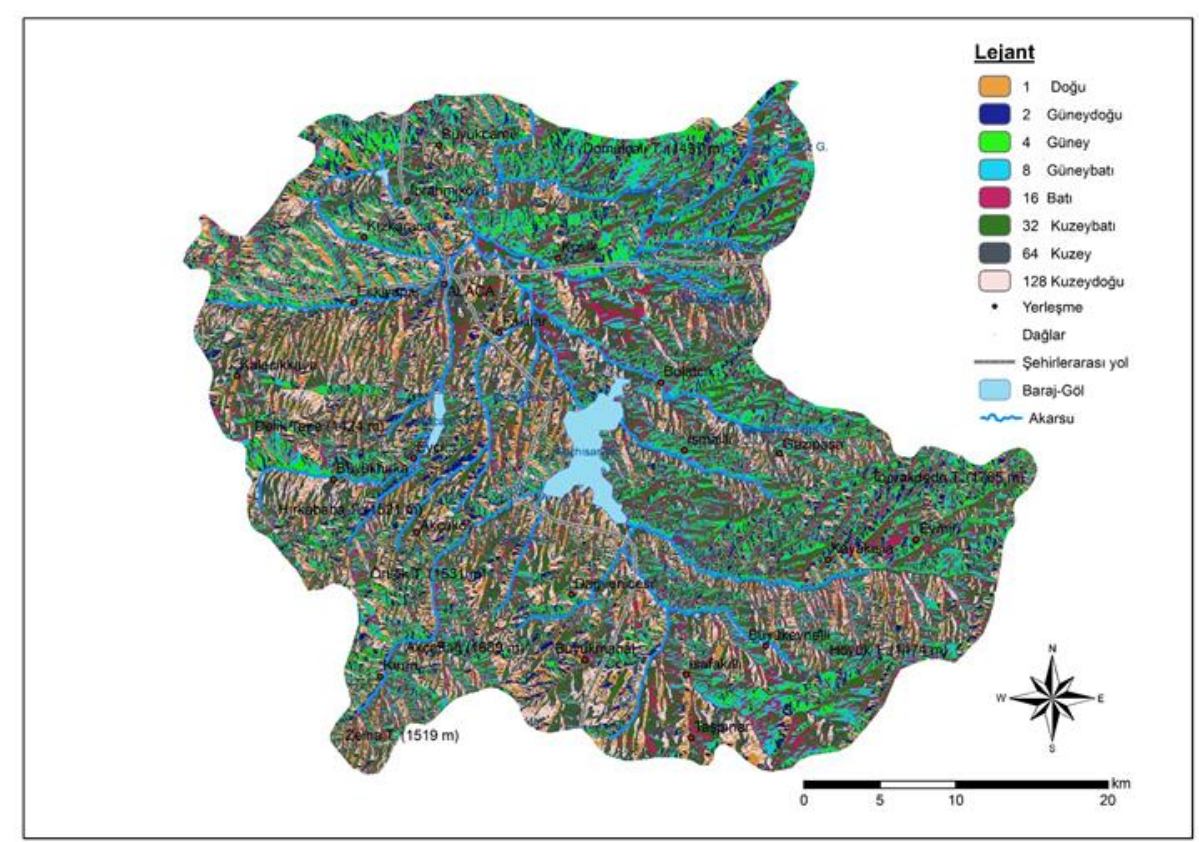

Şekil 2. Doğal Akış Yönleri (Flow Direction)

\section{2. Çatallanma Oranı}

Akarsularda çatallanma oranı havzanın büyüklüğü, yarılma ve eğim derecesi, bulunduğu sahanın iklim özellikleri gibi etkenlere bağlı olarak çeşitlilik göstermektedir (Cürebal, 2004; İmamoğlu, 2016). Bu bağlamda genç akarsu, ana yataktan itibaren birinci, ikinci, üçüncü derece ve diğerleri ile artan bir sıklıkla sahaya yerleşir (Turoğlu, 1997). Herhangi bir sıradaki dere sayısının bir sonraki sıradaki dere sayısına oranını ifade etmek için kullanılır (Rai vd., 2018). Düşük çatallanma oranı varsa hidrograflar keskin ve yüksek, yüksek çatallanma oranı varsahidrograflar düşük ve devamlıdır (Strahler, 1964). Ayrıca dizin çatallanma oranı 3-5 arasında çıkan havzalarda homojen bir jeoloji hakimdir (Verstappen, 1983; Ritter, 2002).

Sayısal yükselti modelinden elde edilen akarsu şebekesine ait özellikler incelenirken Strahler (1964) dizinleri kullanılmıştır. Alaca Çayı havzasının sahip olduğu akarsu ağı ve çatallanma oranı Şekil 3'de ele alınmıştır.

Havzada bulunan birinci ve ikinci dizinler arasında çıkan değerlerin, en yüksek dizin ve bir önceki dizin arasından çıan değerden ne kadar fazla olursa havza içinde oyuk, oyuntu erozyonu şekillerinin (gully) ve dar-derin vadilerin oranıda o kadar fazlalaşır (Verstappen, 1983). Bu durum araştırma sahasında yapılan gözlemlerde doğrulanmış, özellikle birinci dizinlerin bulunduğu sahalarda erozyonal (suya dayalı) şekillerin yaygın olduğu görülmüştür. Araştırmalara göre; birinci ve ikinci dereceli dere sayısı bulunan havzaların çatallanma oranı, daha yüksek derecedeki derelerin çatallanma oranından daha yüksek olduğu belirtilmiş ve bu durumun erozyonal süreçlerinde bir göstergesi olduğu (Verstappen, 1983; Sreedevi vd., 2013; Magesh ve Chandrasekar, 2014) tespit edilmiştir. 


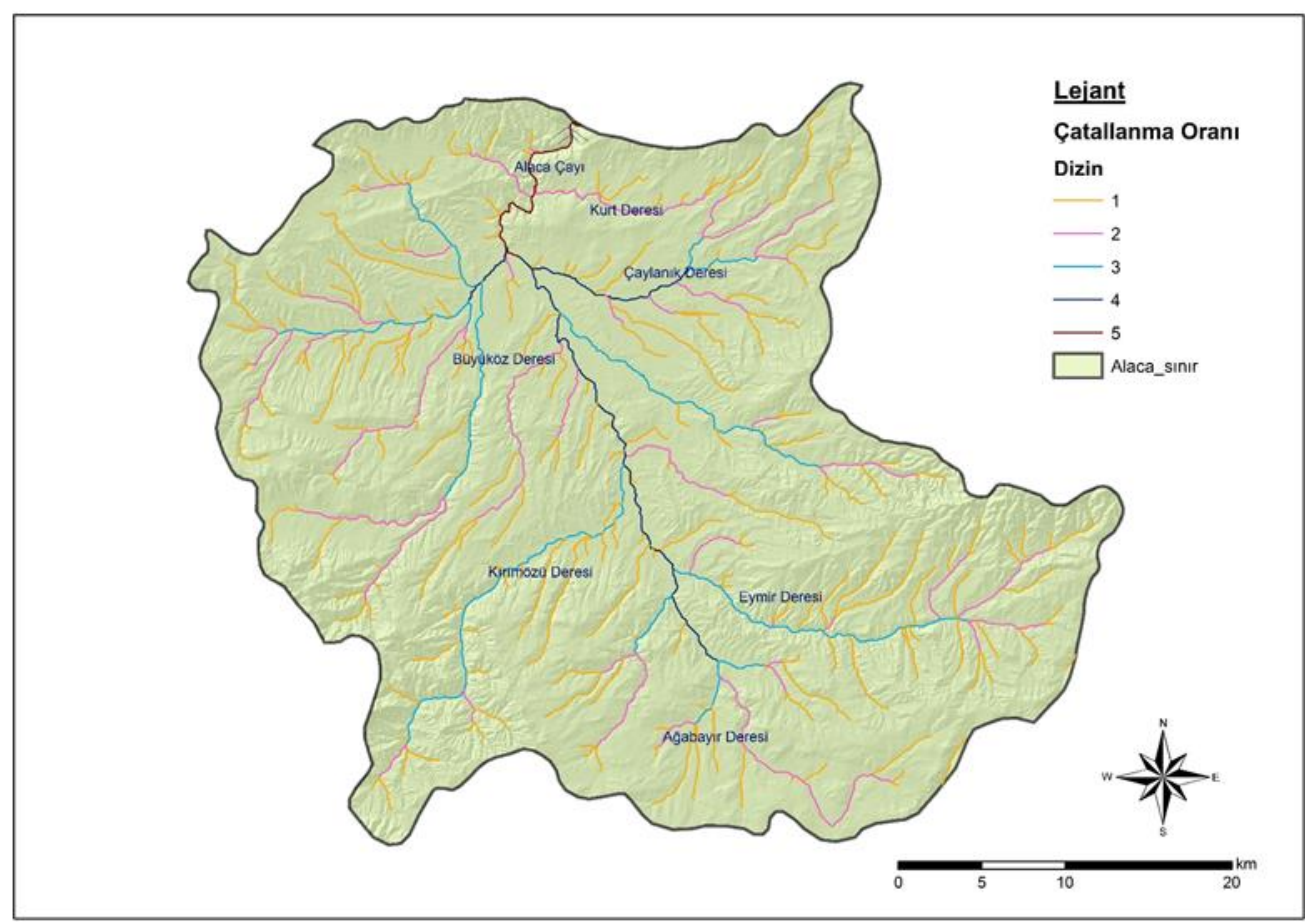

Şekil 3. Strahler metoduna göre üretilmiş çatallanma oranı ve değerleri

\subsection{Hipsometrik Eğri Analizi}

Hipsometrik eğri, yükseltinin akarsu havzası içindeki dağılımını gösterir. Hipsometrik eğriye, toplamdaki havza yüksekliği oranının toplamdaki havza alanı oranı ile birlikte ele alınması sonucu ulaşılır.

Hipsometrik eğrinin dışbükey olması topografyanın genç olduğunu, akarsuların akım gücünün yüksek olduğunu gösterir (İmamoğlu, 2016). Buna göre su erozyonunun yüksek, akarsuyun taşıdığı sediment miktarı ise çok olduğu söylenebilir. Hipsometrik eğrinin içbükey olması ise akarsudaki akım gücünün az olduğunu gösterir. Araştırma saahası hipsometrik eğrisi içbükey özelliktedir. Akım gücü düşük ve taşıdığı sediment miktarı düşük akarsu olarak nitelendirilmektedir. Bu sonuca göre sahada akarsu erozyonunun şiddetli olmadığı düşünülmektedir.

Sahanın hipsometrik eğrisi genel görüntüsü iç bükey özellik göstermektedir. Bu durum akarsuların akımlarının düşük ve taşıdığı malzemenin az olduğunu ortaya koymaktadır. Saha yarı kurak bir iklime sahip olup, akarsular dönemsel olarak bol miktarda su taşımakta, sediment taşınımı da sellenmelerle bağlı değişiklik göstermektedir. Eğimli akarsu vadilerinde, sağnaklarla olan sellenme izleri görülmektedir.

\subsection{Drenaj Yoğunluğu (Dd)}

Drenaj yoğunluğu topografyanın parçalanma derecesini gösterir. Toplam akarsu uzunluğunun, havza alanına bölünmesiyle elde edilir (Horton, 1932, 1945; Verstappen, 1983; Turoğlu, 1997). Drenaj yoğunluğunun düşük olması, derelerin genç oluşumlu olduğunu göstermektedir (Özşahin, 2008). Drenaj yoğunluğunun düşük olduğu sahalar topoğrafyanın nispeten daha alçak olduğu alanlar ve alttaki anakayanın sağlam veya geçirgen olduğu bölgelerdir. Yüksek drenaj yoğunluğu ise genellikle bitki örtüsünün cılız olduğu ya da olmadığı, toprak geçirgenliğinin düşük olduğu alanlarda görülmektedir (Hızal, 1984). Alaca havzası yüzey topraklarında yapılan hidrolik iletkenlik haritasına bakıldığında geçirgenliğin yüksek olduğu sahaların drenaj ağının daha yoğun sahalar olduğu görülmektedir. Drenaj yoğunluğu, havzadaki malzeme taşınımını doğrudan etkilemektedir (Özdemir ve Bird, 2009). Drenajın yoğun olması sahadan taşınan sediment miktarını ve verimli yüzey toprağı kaybını arttırmaktadır. Drenaj yoğunluğu; zeminin geçirgenlik özelliği, infiltrasyon kapasitesi, bitki örtüsü yoğunluğu, relief ve iklimsel faktörlere bağlı olarak değişiklik göstermektedir (Morisawa, 1968). Bu özellikler aynı zamanda toprak erozyonu oluşumunda da etkili olan faktörlerdir.

Havza genelinde Drenaj yoğunluğu değeri 0.4'tür (Tablo 3). Alaca Havzası'nın alansal büyüklüğüne rağmen yoğunluğun düşük olması, yüzey sularının akışa geçmeden önce infiltre olmasına uygun bir ortam olduğunu ortaya koyar.

\subsection{Akarsu Sıklığı (Fu)}

Akarsu sıklığı, alt havzalar ve kollarının havza içinde birim alanda bulunan yatak sayısını ifade eder (Hoşgören, 2004). Toplam dizinin toplam alana bölünmesi sonucu bulunur. Yüksek değerler, geçirimsiz zemini, c1lız bitki örtüsünü gösterirken, düşük değerler ise geçirgenliği ve alçak reliefi ortaya koymaktadır (Hoşgören, 2004; Turoğlu, 1997). Ria vd.,'ne göre (2018) akarsu sıklığını belirleyen temel etken kayaç özellikleri tarafından kontrol edilir. Araştırma sahasında yüksek sıklık değeri görülmektedir. Arazi çalışmaları sırasında da sahanın geçirgenliği düşük zemin özellikleri gösterdiği alanlarda, akarsu erozyonunun yüksek olduğu gözlemlenmiştir. Altıparmak ve Türkoğlu’ na (2018) göre akarsu sıklığının yüksek olduğu yerlerde akarsu yatakları ile vadi sınırları arasındaki mesafe azdır ve pekçok küçük keskin sırt bulunmaktadır. Bu durum arazi çalışmaları sırasında incelenmiş ve araştırma 
sahasının güney doğu ve güneybatı kesiminde havza sınırlarına yakın eğim değerleri yüksek alanlarda akarsu sıklı̆ğının oldukça yüksek olduğu ve küçük sırtlar şeklinde erozyonal oluşumlar olduğu tespit edilmiştir.

\subsection{Tekstür Oranı (T)}

Tekstür oranı havza içindeki toplamdaki birinci dizinin, çevre uzunluğuna bölünmesiyle bulunur (Reddy vd., 2004). T değeri havzanın litolojik yapısına, yüzey geçirgenliğine, havzanın bakı özelliklerine bağlı değiş̧iklik gösterir. Değer yüksek ise 1. düzeydeki kollar fazla, az ise bu kollarda az anlamına gelmektedir. T değeri dairesel havzalarda yüksek, uzunlamasına havzalarda ise düşük değerler gösterir (Özdemir, 2001). Alaca havzası tekstür oranı 0.6 olarak bulunmuştur. Bu oran yükseldikçe sahada yüzeysel akış ve buna bağlı olarak görülecek erozyon olayları artmaktadır. Araştırma sahasında 1. düzeydeki kolların oldukça fazla olduğu buna bağlı olarak sahada diğer şartların da uygun olduğu alanlarda erozyon miktarının yüksek olduğu görülmüştür.

\subsection{Havza Reliefi}

Havzada relief özelliklerinin ve havza eğiminin önemini belirten birçok çalışma yapılmıştır (Horton, 1945; Strahler, 1964; Baker vd., 1988). Havza reliefi havzanın maksimum yüksekliğinden minimum yüksekliğinin çıkarılması sonucu elde edilir (Tablo 5). Araştırma sahasının havza relief oranı 938.08'dir (Tablo 6). Relief değerinin artması daha dik yamaçların görülmesine ve eğimli yatağa sahip akarsuların artmasına yüzeysel akışın hızlanmasına ve taşkın değerlerinin yükselmesine sebep olur (Baker vd., 1988). Bu durum havzada güney kesimlerde yüksek değerler oluşmasına zemin hazırlamıştır. Buna bağlı olarak havza güneyinde erozyonal süreçlerin etkinliği daha yüksektir.

\subsection{Engebelilik Değeri (Rn)}

Engebelilik değeri (Rn) havzanın infiltrasyon sızma kapasitesi yüzeysel akış durumu ve erozyonal süreçler hakkında bilgi verir (Reddy vd., 2004). Havzada engbelilik fazla ise erozyonal faaliyetler için uygun bir ortamdır. Ayrıca yüksek engebelilik varsa yüksek sel riskide söz konusudur (Baker vd., 1988). Alaca havzasında engebelilik değeri 375.23’tür. Arazi çalışmaları sırasında yapılan gözlemlerle güneydeki sahalarda engebeliliğe bağlı olarak aşınmanın güçlü olduğu görülmüştür. Fakat tek başına engebelilik değerlerinin yüksek olması erozyonun güçlü olması anlamına gelmemektedir. Araştırma sahası güneybatısında kalan bölgede engebelilik fazla olmasına rağmen buralarda toprağın tekstürel yapısına bağlı olarak infiltrasyon hızı yüksek olduğu için sular yüzeysel akışa geçmeden kaybolmaktadır. Ancak şiddetli sağanak yağmurlar olduğunda engebelilik suların yüzeysel akışa geçmesi açısından önem arzetmektedir.

\subsection{Havza Şekli}

Havzanın şekil özelliği akarsuların akım grafiğini doğrudan etkileyen parametrelerden biridir (Verstappen, 1983). Bunun için havzanın nas bir şekle sahip olduğu önemlidir. Havza uzun ve dar yan kollara sahipse bu kollardan ana akarsuya akım farklı zamanlarda ulaşmakta ve bu nedenle de taşkın riski az olmaktadır. Geniş ve yuvarlak şekilli havzalarda kollardan gelen akım ana kola neredeyse aynı anda ulaştığı için akım değerleri birden yükselmekte ve havzada sağanak yağışlar sonrasında taşkın meydana gelmektedir (Atalay, 1986).

Havza şekli ile ilgili farklı formüller ortaya konulsada havza uzunluğu, çevre uzunluğu alan gibi parametreler her formülde kullanılmıştır. Bu araştırmada CBS yardımı ile hesaplanmış formüller ve sonuçları Tablo 5'te verilmiştir.

\subsection{0. Şekil İndeks (Sw) Değeri}

İnceleme alanında, şekil indeks (Sw) değeri 1.99'dur. Bu özellik havza alanı ile uzunluğu arasındaki ilişsiye dayanmaktadır. Alan büyüdükçe şekil faktörü küçülmekte, uzunluk arttıkça yükselmektedir.

\subsection{Gravelius İndeks (Kc)}

Gravelius indeksine göre; sonuç değer ne kadar küçükse havza o kadar dairesel bir görünüm arz eder (Hoşgören, 2001). Uzunlamasına ve dairesel havzalarda farklı Kc değeri ortaya çıkmaktadır (Şekil 4).

Buna göre Alaca havzasının değeri 0.06 'dır. Kc değerlerine ait şekillere baktığımızda en küçük Kc değerinden daha küçük olan havza değeri araştırma sahasının daireselliğinin oldukça yüksek olduğunu göstermektedir. Dairesel şekilli havzalarda, toplanma zamanı kısa olacağından, kısa sürede yüksek akımlar oluşacaktır (Veeranna vd., 2017). Yüksek akım görülen alanda ise erozyonal süreçlerin hızla gerçekleşmesi olağan bir durumdur. Alaca Havzası gravelius indeksi sonucuna göre dairesel görünümlü yüzeysel akışın daha etkin olduğu ve buna bağlı olarakta yüzeysel erozyonun fazla olduğu havza tipine girmektedir. Bu bilgiler ile arazi çalışmalarındaki gözlemler birleştirildiğinde birebir örtüştüğü, havzada çizgisel erozyondan ziyade yüzeysel erozyonun daha etkili olduğu görülmüştür (Şekil 27). 


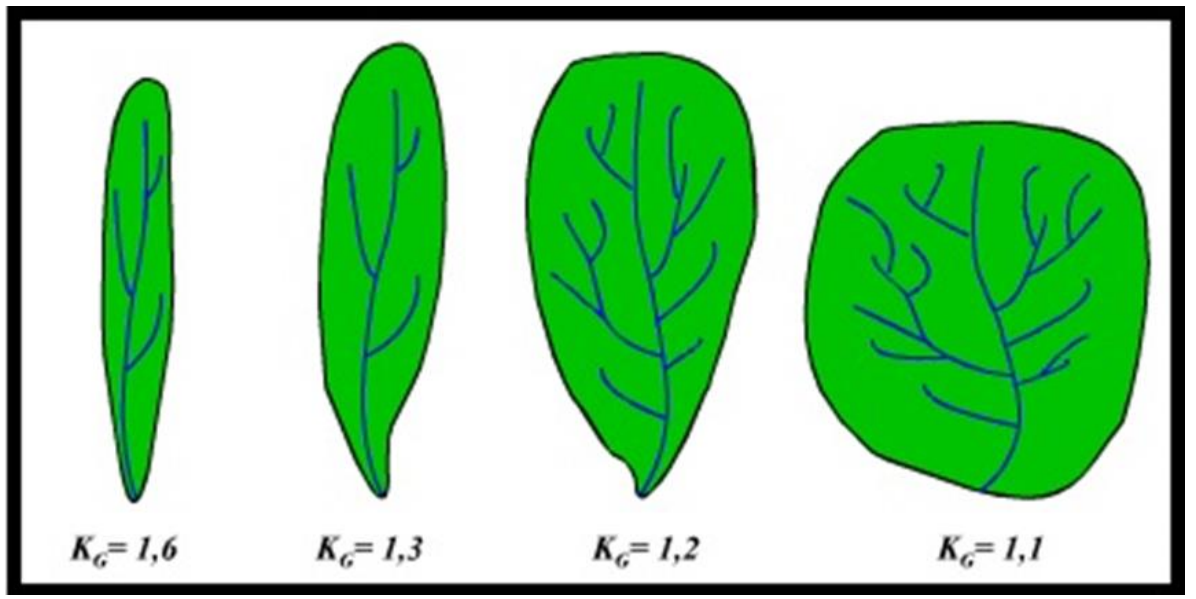

Şekil 4. Farklı Kc değerlerine sahip havzalar (Musy, 2001). Bu şekillerden ince ve uzun olanlarda çizgisel erozyon, konkav ve oval olanlarda ise yüzey erozyonu daha şiddetli olmaktadır.

\subsection{Uzunluk Oranı}

Uzunluk oranı; havzanın infiltirasyonu ve yüzeysel akışı hakkında bilgi verir. Yüksek değerler geçirgenliğin fazla ve yüzeysel akışın az olduğunu, düşük değeler ise erozyonun yüksek olduğunu ve fazlaca malzeme taşındığını ortaya koyar (Reddy vd., 2004). Balcı ve Özyuvacı (1988) uzunluk değerinin 1 olmasının alçak topoğrafyayı temsil ettiği belirtmişlerdir. Havza genelinde Re 0.91 'lik bir değer göstermektedir (Tablo 4). Bu durum havzanın dairesel şeklini doğrulamaktadır. Öte yandan havza genelinde olmasa da yüksek kesimlerde ve eğimli sahalarda erozif etkilerin fazla olduğuda arazi çalışmalarında gözlenmiş buralardaki alt havzaların uzunluk oranlarının daha düşük değerler göstereceği düşünülmektedir.

\subsection{Form Faktörü}

Form faktörü düşük havzalar; yan kollardan kısa sürede gelen akımla, uzun süreli yüksek ana akımın görüleceği bir şekil özelliği gösterir. Form faktörü yüksek ise uzun sürede yan kollardan gelen yüksek akımla, kısa süreli düşük ana akımın görüldüğü ve kısa süreli maksimum akıma neden olan bir şekil ortaya çıkar (Reddy vd., 2004; Biswas vd.,1999).

Havza form faktörü 0,89 'dur. Bu değer havzada yan kollardan gelen yüksek akımla, kısa süreli maksimum akımlara neden olan bir şekle sahiptir. Bu da akarsuda zaman zaman taşkınlar olabileceğini göstermektedir. Bu durum ani yükselimlerle birlikte şiddetli bir malzeme taşımına işaret etmektedir. Akarsu yataklarında bol miktarda görülen çakıl depolarıda bu durumu doğrular niteliktedir.

Tablo 2. Alaca havzası akarsu ăg ve reliefi

\begin{tabular}{|c|c|c|c|c|c|c|c|c|c|c|c|}
\hline & 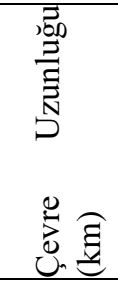 & 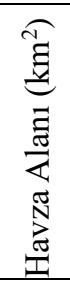 & 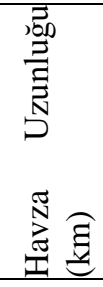 & 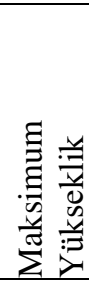 & 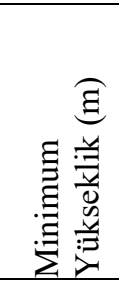 & & & 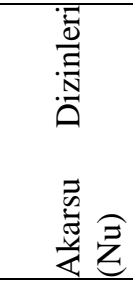 & & 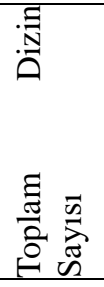 & 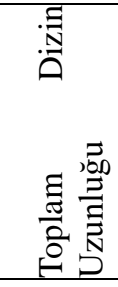 \\
\hline 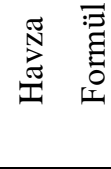 & $\Theta$ & 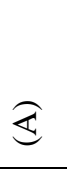 & 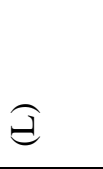 & 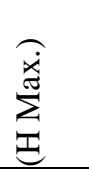 & $\underset{\Xi}{\dot{\Xi}}$ & 1 & 2 & 3 & 5 & $\widehat{\widetilde{\mathrm{Z}}}$ & 包 \\
\hline 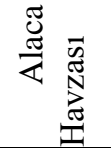 & $\begin{array}{l}\infty \\
\stackrel{8}{0} \\
\text { iे } \\
\text { i }\end{array}$ & $\stackrel{\infty}{0}^{\infty}$ & 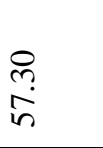 & $\begin{array}{l}\hat{n} \\
\text { ָ̊ } \\
\end{array}$ & 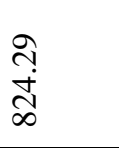 & 124 & 5 & 2 & & 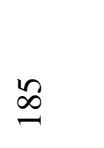 & $\begin{array}{l}0 \\
\text { ñ. } \\
\text { శ్ }\end{array}$ \\
\hline
\end{tabular}

Tablo 3. Topoğrafya haritasından üretilmiş akarsu ăg ve reliefi

\begin{tabular}{|c|c|c|c|c|c|c|}
\hline & 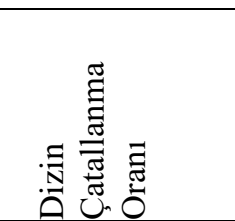 & 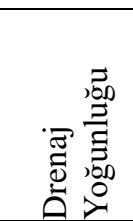 & 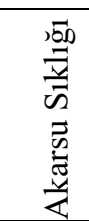 & 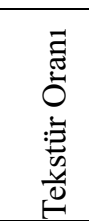 & 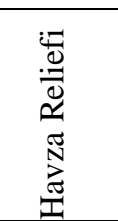 & 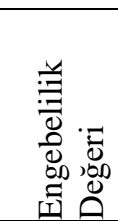 \\
\hline $\begin{array}{l}\text { Alaca } \\
\text { Havzas }\end{array}$ & 2.73 .7433 .3 & 0.4 & 0.1 & 0.6 & 938.08 & 375.23 \\
\hline
\end{tabular}


Tablo 4. Alaca havzası şekil analiz tablosu

\begin{tabular}{|c|c|c|c|c|c|c|c|c|}
\hline & 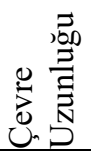 & 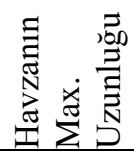 & 疍 & 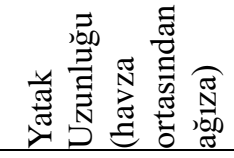 & $=\frac{\vec{n}}{\frac{\pi}{0}}$ & 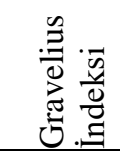 & 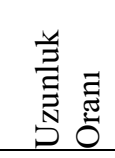 & हृ: \\
\hline $\begin{array}{l}\text { Alaca } \\
\text { Havzası }\end{array}$ & 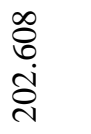 & $\begin{array}{l}\infty \\
\sim \\
\sim\end{array}$ & กิ & in & ฮे & $\stackrel{0}{0}$ & $\bar{a}$ & $\stackrel{0}{\infty}$ \\
\hline
\end{tabular}

\section{Sonuç}

Çalışma alanı İç Anadolu Bölgesi, Orta Kızılırmak Bölümü kuzey kesiminde bulunmaktadır. Araştırma sahası Alaca havzasının tamamından oluşmaktadır. Havza Yeşilırmak'ın su toplama havzasında bulunmaktadır. Araştırma alanı Alaca Çayı tarafından drene edilmektedir. Alaca havzasının toplam alanı $1656.4 \mathrm{~km}^{2}$ 'dir. Araştırma sahası yükselti değerleri $825 \mathrm{~m}$ ile $1726 \mathrm{~m}$ arasında değişmektedir.

Akarsu havzasında yapılan morfometrik analizler sonucunda; çatallanma oranına göre birinci dizinlerin bulunduğu sahalarda erozyonal şekillerin yaygın olduğu görülmüştür. Havza genelinde Drenaj yoğunluğu (Dd) değeri 0.4'tür. Alaca havzasının alansal büyüklüğüne rağmen yoğunluğun düşük olması, yüzey sularının hızlıca infilltre olmasına uygun zemin olduğu sonucunu ortaya koymuştur. İmamoğlu vd., (2016) yaptıkları çalışmada da sahada aşınım değeri ile tekstürel özellikler arasında yüksek önem tespit etmiştir. Alaca havzası tekstür oranı 0.6 olarak bulunmuştur. Bu oran yükseldikçe sahada yüzeysel akış ve buna bağlı olarak görülecek erozyon olayları artmaktadır. Havzanın yükselti ve eğim değerlerinin arttığı yerlerinde erozif faaliyetler artarken havza şekline bağlı olarak özellikle eğim değerlerinin düştüğü yerlerde erozyon miktarı düşüktür. Bu durum arazi çalışmaları sırasında kontrol edilmiş ve sahada İmamoğlu vd. (2017) tarafından yapılan çalışma sonuçları ile de uyum gösterdiği görülmüştür. İnfilttrasyonun yüksek olmasına rağmen, engebeli yerlerde şiddetli sağanak yağışlar sonrasında yüzeysel akışa geçen sular erozyona sebep olmaktadır. Havzanın yuvarlak şekline bağlı olarak zaman zaman sağanak yağışlar sonrasında akarsu seviyesi aniden yükselmekte ve şiddetli erozyon yaşanmaktadır. Dairesel görünümlü havzalarda yüzeysel akışın daha etkin olduğu buna bağlı olarakta yüzeysel erozyonun çizgisel erozyona göre daha etkin olduğu tespit edilmiştir. Havza genelinde olmasa da yüksek kesimlerde ve eğimli sahalarda erozif etkilerin fazla olduğu görülmüş, buralardaki alt havzaların uzunluk oranlarının düşük değerlere sahip olacağı öngörülmüştür.

Burada elde edilen sonuçlar arazi çalışmaları sırasında incelenmiş ve doğrulukları sahada test edilmiştir. Bu çalışma erzoyonal süreçlerinin incelenmesi konusunda morfometrik indislerin önemini ortaya koymaktadır.

\section{Kaynakça}

Agarwal, C.S. (1998). Study of Drainage Pattern Through Aerial Data İn Navgarh Area Of Varanasi District, U.P. Journal Indian Society of Remote Sensing, 26: 169-175.

Altıparmak, S. ve Türkoğlu, N. (2018). Yakacık Çayı Havzasının (Hatay) Morfometrik Analizi. Ankara Üniversitesi Dil ve TarihCoğrafya Fakültesi Dergisi, 58(1), 353-374.

Atalay, İ. (1986). Uygulamalı hidroğrafya. Ege Üniversitesi, Edebiyat Fakültesi Yayınları, Yayın No: 38, İzmir.

Avcı , V. ve Sunkar, M. (2017). Jeomorfik İndislerle Varto Havzası'nda (Muş) Tektonik Aktivitenin Belirlenmesi. Türk Coğrafya Kurumu 75. Kuruluş Y1lı Kongresi Tam Metin Bildiriler Kitabı (s. 730 - 742). Ankara: Türk Coğrafya Kurumu.

Avcı, V. ve Günek, H. (2015). Uludere Havzası'nın (Bingöl) Jeomorfolojik Özelliklerinin Belirlenmesinde Morfometrik Analizlerin Kullanımı. Adıyaman Üniversitesi Sosyal Bilimler Enstitüsü Dergisi(21), 745-766.

Aydın, A. (2008). Büyük Menderes nehri sağ sahil derelerindeki sel kontrol çalışmalarının irdelenmesi, Doktora Tezi, İstanbul Üniversitesi, Fen Bilimleri Enstitüsü, İstanbul.

Bahadır, M., Uzun, A., Zeybek, H.İ. ve Hatipoğlu, İ.K. (2017). Terme Çayı Havzası'nın Morfometrik Analizi, (Ed) Yılmaz, C., Terme Araştırmaları, Serander Yayınları, Trabzon.

Bahadir, M. ve Özdemir, M. A. (2011). Acıgöl Havzası'nın Sayısal Topoğrafik Analiz Yöntemleri İle Morfometrik Jeomorfolojisi. Journal of International Social Research, 4(18).

Baker, V.R. Kochel, R.C., Paton, P.C. (1988). Flood Geomorphology. John Wiley \& Sons, USA.

Balcı, N., Özyuvac1, N. (1988). Havza Amenajmanı II. İ.Ü. Orman Fakültesi, Yüksek Lisans Ders Notları, İstanbul.

Bharadwaj A.K., Pradeep. C., Thirumalaivasan D., Shankar C.P., Madhavan N. (2014). Morphometric Analysis Of Adyar Watershed. IOSR Journal of Mechanical and Civil Engineering (IOSR-JMCE), 71-77.

Biswass, S., Sudhakar, S. and Desai V.R. (1999). Prioritisation Of Subwatersheds Based On Morphometric Analysis Of Drainage Basin: A Remote Sensing And GIS Approach. Journal of the İndian Society of Remote Sensing, Vol. 27, No:3, p. 155-166.

Cürebal, İ. (2004). Madra Çayı'nın Hidrografik Özelliklerine Sayısal Yaklaşım. Balıkesir Üniversitesi Sosyal Bilimler Enstitüsü Dergisi, Sayı:11, 11-24.

Elbaşı, E., Özdemir, H. (2018). Marmara Denizi Akarsu Havzalarının Morfometrik Analizi. Cografya Dergisi, 36, 63-84.

Eraslan, S., İmamoğlu, A., Çoşkun, A., Saygın, F. ve Dengiz, O. (2017). İnebolu Havzası Topraklarının Erozyon Duyarlılık Durumları ve Arazi Kullanımı/Arazi Örtüsü ile Olan İlişkisinin Belirlenmesi. Yüzüncü Yıl Üniversitesi Tarım Bilimleri Dergisi, 27(1), 95108. 
Erol Görür, A., Karadeniz, C. (2018). Morfometrik Parametrelerin Havza Hidrolojisi Bakımından Değerlendirilmesi. Turkish Journal of Forestry, 19(4): 447-454.

Fural, Ş. (2018). Acısu Çayı'ın (Serik-Antalya) Drenaj Özelliklerinin Morfometrik Analizi, Jass Studies-The Journal of Academic Social Science Studies, Number: 72 Autumn III 2018, p. 541-556.

Ghany, M.K.A. (2015). Quantitative Morphometric Analysis Of Drainage Basins Between Qusseir and Abu Dabbab

Gravelius, H. (1914). Grundrifi Der Gesamten Gewcisserkunde. Band I: Flufikunde (Compendium of Hydrology, vol. I.

Hızal, A. (1984). Havza Fotoğrafları Yorumlamasının Havza Amenajmanı (Ova Deresi Havzası, Kocaeli) Çalışmalarında Uygulanma Olanaklarının Araştırılması. İstanbul Üniversitesi Yayın No: 3144, Orman Fakültesi Yayın No: 341, İstanbul, s. 190.

Horton, R.E. (1932). Drainage basin characteristics. Trans. American Geophysical Union 13: 350-361.

Horton, R.E. (1945). Erosional Development Of Stream And Their Drainage Basin. Hydrogeological Approach To Quantitative Morphology, Bulleting of Geological Society of America, 56: 275-361.

Hoşgören, M. Y. (2001). Hidroğrafyanın Ana Çizgileri I- Yeraltısuları- Kaynaklar- Akarsular. İstanbul, Çantay Kitabevi.

Hoşgören, M. Y. (2004). Hidrografyanın ana çizgileri II, Göller. Çantay Kitabevi, ISBN 975-7206-85-7. İstanbul.

İmamoğlu, A. (2016). Alaca Havzası'nın Eroz-yon Risk Değerlendirmesi ve Planlaması, Ondokuz Mayıs Üniversitesi, Sosyal Bilimler Enstitüsü, Yayınlan-mamış Doktora Tezi, Samsun.

İmamoğlu, A., Bahadır, M. ve Dengiz, O. (2016). Çorum Alaca Havzasında Toprak Erozyon Duyarlılık Faktörünün Farklı Enterpolasyon Modeller Kullanılarak Konumsal Dağılımlarının Belirlenmesi. Toprak Su Dergisi, 5(1).

İmamoğlu, A., Bahadır, M. ve Dengiz, O. (2017). Alaca Havzasında Uygulanan Rusle Erozyon Modelinde, C Faktörünün (Arazi Örtüsü /Arazi Kullanımı) Zamansal Değişimi ve Toprak Kaybına Etkisi, International Journal of Social Science, Number: 61 , p. 321-336.

Keller, E.A. vr Pinter, N. (2002). Active Tectonics Earthquakes, Uplift, and Landscape, Second Edition, Prentice Hall, New Jersey.

Köle, M. M. (2016). Devrez Çayı Vadisinin Tektonik Özelliklerinin Morfometrik İndisler İle Araştırılması. Coğrafya Dergisi, (33), 2036.

Kumar, R., Lohani, A.K., Nema, R.K., Singh, R.D. (2000). Evaluation of Geomorphological characteristics of catchment using GIS. GIS India, 9 (3): 13-17.

Magesh, N.S., Chandrasekar, N. (2014). GIS Model-Based Morphometric Evaluation Of Tamiraparani Sub-Basin, Tirunelveli District, Tamil Nadu, India. Arab J. Geosci, 7: 131-141.

Maidment, D.R. (2002). ArcHydro GIS For Water Resources. Esri Press, Califormia.

Martins, A. K., Gadiga, B. L. (2015). Hydrological and Morphometric Analysis Of Upper Yedzaram Catchment of Mubi in Adamawa State, Nigeria. Using Geographic Information System (GIS), World Environment 5(2): 63-69.

Morisawa, M. (1968). Streams: Their Dynamics And Morphology. New York: McGraw Hill.

Musy, A. (2001). Ecole Polytechnique Fédérale, Lausanne, Suisse.

Özdemir, H and Bird, D. (2009). Evalution of Morphometric Parameters Of Drainage Network Drived From Topographic Maps And DEM İn Point Of Flood. Environmental Geology 56, 1405-1415.

Özdemir, H. (2001). Havza Morfometrisi Ve Taşkınlar. Fiziki Coğrafya Araştırmaları: Sistematik ve Bölgesel Türk Coğrafya Kurumu Yayınları, Sayı: 6, s. 507-526.

Özdemir, H. (2007). Havran Çayı Havzasının (Balıkesir) CBS ve Uzaktan Algılama Yöntemleriyle Taşkın Ve Heyelan Risk Analizi, Doktora Tezi, İstanbul Üniversitesi, Sosyal Bilimler Enstitüsü, Coğrafya Anabilim Dalı, İstanbul.

Özdemir, H. (2011). Havza morfometrisi ve taşkınlar, Fiziki Coğrafya Araştırmaları; Sistematik ve Bölgesel, Türk Coğrafya Kurumu Yayınları, 5, 507-526, İstanbul.

Özsahin, E. (2008). Keçidere (Gönen Çayı'nın bir kolu) Havzasının Hidrografik Özelliklerine Sayısal Yaklaşım. Mustafa Kemal Üniversitesi Sosyal Bilimler Enstitüsü Dergisi, 5 (10): 301-317.

Rai, P.K., Chandel, R.S., Mishra, V.N, Singh, P. (2018). Hydrological İnferences Through Morphometric Analysis Of Lower Kosi River Basin Of India For Water Resource Management Based On Remote Sensing Data. Applied Water Science, 8:15,

Reddy, G.P. O., Maji A.K., Gajbhiye K.S. (2002). GIS For Morphometric Analysis Of Drainage Basins. GIS India, 4: 9-14.

Ritter, D.F., Kochel, R.C., Miller, J.R. (2002). Process geomorphology. Fourth Edition, McGraw- Hill.

Sreedevi, P.D., Sreekanth, P.D., Khan, H.H., Ahmed, S. (2013). Drainage Morphometry And İts İnfluence On Hydrology İn A SemiArid Region: Using SRTM Data And GIS. Environmental Earth Sciences, 70(2):839-848.

Strahler, A.N. (1964). Quantitative Geomorphology Of Drainage Basins And Channel Networks. In: V. T. Chow (Ed.) New York: McGraw Hill, Handbook of Applied Hydrology, pp. 4-76

Tarboton, D.G., Bras, R.L. and Rodriguez-Iturbe, I. (1991). On the extraction of channel networks from digital elevation data. Hydrological Processes. Volume: 5, 81-100.

Turoğlu, H. (1997). İyidere Havzasının Hidrografik Özelliklerine Sayısal Yaklaşım. Türk Coğrafya Dergisi, Sayı:32, İstanbul, s. 355364.

Turoğlu, H. (2016) Coğrafi Bilgi Sistemlerinin Temel Esasları (Genişletilmiş 4. Baskı). ISBN 987-975-9060-51-0, Çantay Kitapevi, İstanbul.

Turoğlu, H. ve Aykut, T. (2019). Ergene Nehri Havzası için Hidromorfometrik Analizlerle Taşkın Duyarlılık Değerlendirmesi. Jeomorfolojik Araştırmalar Dergisi, (2), 1-15.

Turoğlu, H. (2007). Flood And Flash Flood Analysis For Bartın River Basin Management, 22-24 Mart, Antalya-Türkiye, http://www2.dsi.gov.tr/english/congress2007/chapter_4/113.pdf

Utlu, M. ve Özdemir, H. (2018) Havza Morfometrik Özelliklerinin Taşkın Üretmedeki Rolü Biga Çayı Havzası Örneği, Coğrafya Dergisi - Journal of Geography, 36, pp. 49-62. 
Uzun, M. (2014). Lale Dere (Yalova) Havzası'nın Jeomorfolojik Özelliklerinin Jeomorfometrik Analizlerle İncelenmesi, Route Educational and Social Science Journal, 1(3), October.

Veeranna, J., Gouthami, K., Yadav, P. B.,Mallikarjuna, V.R. (2017). Calculating Linear And Areal And Relief Aspect Parameters Using Geo-Spatial Techniques (ArcGIS 10.2 and SWAT model) for Akkeru River Basin Warangal. International Journal of Current Microbiology and Applied Sciences, 6 (10): 1803-1809.

Verstappen, H. (1983). Applied Geomorphology: Geomorphological Surveys for Environmental Development. Elsevier, New York.

Withanage, N.S., Dayawansa, N.D.K., De Silva R.P. (2014). Morphometric Analysis Of The Gal Oya River Basin Using Spatial Data Derived From GIS. Tropical Agricultural Research, 26 (1), 175-188. 